\title{
IDENTIFIKASI ARTI TANGIS BAYI VERSI DUNSTAN BABY LANGUAGE MENGGUNAKAN JARAK TERPENDEK DARI JARAK MAHALANOBIS (Infant Cries Identification of Dunstan Baby Language Version using the Shortest Distance of Mahalanobis)
}

\author{
${ }^{1}$ Medhanita Dewi Renanti \\ ${ }^{1}$ Program Diploma Institut Pertanian Bogor, medha_nuha@yahoo.com
}

Diterima 7 Oktober 2013/ Disetujui 21 Oktober 2013

\begin{abstract}
New born babies have the ability to express their basic needs through sounds. A system to understand the meaning of crying infants of aged 0-3 months is called Dunstan Baby Language (DBL), which was introduced in 2006. This research aimed to perform the modeling of codebook method with $k$-means clustering technique as feature matching, and Mel Frequency Cepstrum Coefficients (MFCC) as feature extraction to identify the infant cries. The infant cries identification of Dunstan Baby Language version used the shortest distance of mahalanobis. The treatment in this research was the combination of frame length: $25 \mathrm{~ms}$, $40 \mathrm{~ms}$ and $60 \mathrm{~ms}$, frame overlap of $0 \%, 40 \%$, and $60 \%$, and the number of codewords (number of clusters) of 1 to 29. The best accuracy in recognizing five types of crying Infants using mahalanobis distance can be achieved up to $83 \%$ when the frame length $=275$, the overlap frame $=0.25$, and the $k=17$. Sound 'heh' was the most familiar, whereas sound 'owh' was always missunderstood and generally known as 'neh' and 'eairh'.
\end{abstract}

Keywords: Codebook, Dunstan baby language, Mahalanobis Distance, MFCC

\section{PENDAHULUAN}

Dunstan (2006) menyatakan bahwa setiap bayi lahir mempunyai kemampuan untuk mengekspresikan kebutuhan dasar mereka melalui suara. Penelitian yang dilakukan oleh Priscilla Dunstan dari tahun 1998 sampai 2006 telah berhasil menemukan bahasa yang dimiliki oleh semua bayi di seluruh dunia usia 0-3 bulan. Bahasa tersebut dikenal dengan sebutan Dunstan Baby Language-DBL.

Terdapat lima bahasa bayi versi DBL yaitu: "neh" berarti lapar, "owh" berarti lelah yang mengindikasikan bayi sudah mulai mengantuk, "eh" berarti ingin bersendawa, "eairh" berarti nyeri (ada angin) di perut, dan "heh" berarti tidak nyaman (bisa karena popoknya basah, udara terlalu panas atau dingin, atau hal lainnya). Perintis DBL di Indonesia adalah dokter Adhiatma Gunawan yang menyebutkan bahwa seorang bayi mempunyai refleks primitif yang dimiliki sejak dilahirkan. Refleks ini bersifat universal dan lambat laun akan menghilang seiring dengan berkembangnya kemampuan untuk beradaptasi. DBL berlaku pada bayi hingga usia tiga bulan karena setelah usia tersebut bayi akan mengembangkan kemampuan berkomunikasinya sendiri dengan bantuan orang tua dan lingkungan. Penelitian membuktikan bahwa $90 \%$ dari ibu-ibu di seluruh dunia yang mengikuti DBL merasa puas dan terbantu dengan sistem tersebut dan merekomendasikan pada yang lain. Sementara lebih dari $70 \%$ orang tua merasa lebih percaya diri dalam mengasuh bayinya dan by the end of the day, tingkat stres mereka berkurang signifikan (Gunawan 2011).

Kepakaran untuk menentukan arti tangis bayi versi DBL masih agak jarang sehingga informasi arti tangis bayi ini belum mudah didapatkan oleh para orang tua. Saat ini sistem untuk mentrasfer pengetahuan mengenai $\mathrm{DBL}$ dengan cara mengikuti pelatihan atau seminar yang diadakan oleh pengelola atau dengan cara mempelajari sendiri materi jenis tangis bayi versi DBL dalam bentuk optical discs atau dapat juga mengunduh materi DBL di internet. Pengguna sistem DBL khususnya di Indonesia akan lebih yakin dengan kesimpulan yang mereka buat jika ada suatu software yang secara otomatis dapat menghasilkan arti tangisan bayinya. Hal ini dapat menguatkan kesimpulan mereka, karena jika hanya mengikuti pelatihan kilat atau seminar, masih ada beberapa peserta yang belum paham bagaimana mengenali maksud tangisan bayi tersebut atau belum tepat memaknai tangisan bayi. Selain itu nantinya software ini juga bisa bermanfaat bagi orang tua yang belum mengikuti pelatihan atau seminar DBL sehingga para orang tua dapat memahami bahasa/tangis bayi.

Penelitian mengenai tangis bayi telah dilakukan oleh para peneliti, antara lain: klasifikasi tangis bayi bayi normal dan abnormal (menderita gangguan hipoksia-tubuh kekurangan oksigen) menggunakan neural network menghasilkan akurasi 85\% (Poel \& Ekkel 2006). Klasifikasi bayi sehat dan bayi yang mengalami sakit seperti kerusakan otak, bibir sumbing, hidrosefalus, dan sindrom kematian bayi mendadak menggunakan metode klasifikasi Hidden Markov Model-HMM menghasilkan akurasi 91\% (Lederman et al. 2008). Penelitian lainnya adalah klasifikasi tiga jenis tangis yaitu bayi normal, bayi tuli, dan bayi yang menderita asfiksia (tidak dapat bernafas secara spontan dan teratur) pada usia satu hari sampai sembilan bulan menggunakan neural network menghasilkan akurasi 86\% (Reyes-Galaviz dan Reyes-Garcia 2004).

Dari beberapa hasil penelitian tersebut dapat disimpulkan bahwa tangisan bayi berarti sinyal suara tangis bayi dapat digunakan untuk mendeteksi status kesehatan bayi. Hal ini sejalan dengan penelitian yang dilakukan oleh Priscilla Dunstan yang menyatakan bahwa tangis bayi sebagai alat komunikasi untuk memenuhi kebutuhan atau keinginannya dan tangis bayi mempunyai tujuan untuk mengungkapkan sesuatu.

Penelitian klasifikasi tangis bayi sebelumnya telah menggunakan neural network atau HMM sebagai pengenal polanya. Penelitian untuk identifikasi jenis bayi versi DBL ini menggunakan codebook untuk pengenal 
polanya dan Mel-Frequency Cepstrum Coefficients (MFCC) untuk ekstraksi ciri. Pemilihan metode ini didasari beberapa penelitian diantaranya: penelitian Lee et al. (2006) melakukan pengenalan suara burung menggunakan MFCC dan Vector Quantization (VQ) codebook dan berhasil mencapai akurasi 87\%. Selain itu speaker recognition system juga berhasil dibuat menggunakan MFCC dan VQ (Kumar 2011). Penelitian serupa dilakukan oleh Singh dan Rajan (2011) yang berhasil mencapai akurasi 98,57\% dengan melakukan penelitian speaker recognition menggunakan VQ dan MFCC.

\section{METODOLOGI}

Metode penelitian ini terdiri atas beberapa tahapan proses yaitu pengambilan data, preprocessing, pemodelan codebook tangis bayi, pengujian dan analisis, serta pembuatan antarmuka. Metodologi penelitian proses identifikasi jenis tangis bayi ditampilkan pada Gambar 1.

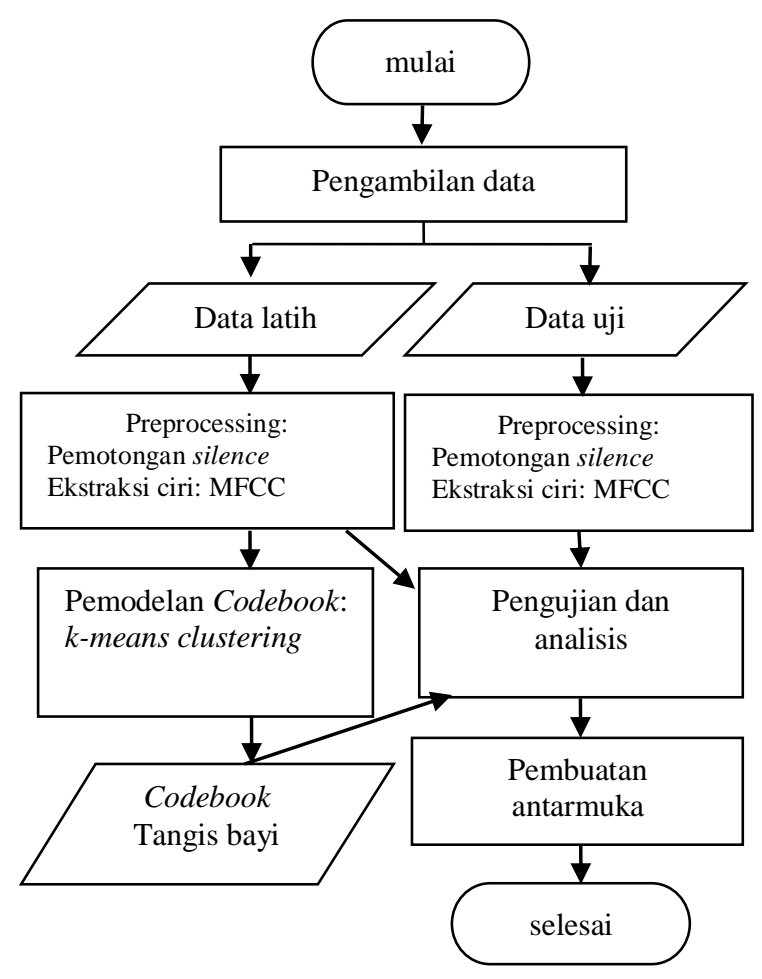

Gambar 1 Metodologi penelitian identifikasi arti tangis bayi

\section{Pengumpulan Data}

Data yang digunakan untuk penelitian ini adalah diambil dari video Dunstan Baby Language yang sudah dilakukan pengolahan data. Data terbagi menjadi dua yaitu data latih dan data uji. Terdapat 140 data latih yang masing-masing mewakili 28 tangis bayi lapar, 28 tangis bayi mengantuk, 28 tangis bayi ingin bersendawa, 28 tangis bayi mengalami nyeri (ada angin) di perut, dan 28 tangis bayi tidak nyaman (bisa karena popoknya basah/udara yang terlalu panas/dingin atau hal lainnya). Data uji sebanyak 35 , masing-masing 7 tangis bayi untuk setiap jenis tangis bayi. Sampling rate yang digunakan pada penelitian ini adalah $11000 \mathrm{~Hz}$. 


\section{Preprocessing}

Pada tahap preprocessing ini dilakukan pemotongan silence dan ekstraksi ciri menggunakan metode Mel Frequency Cepstrum Coefficients (MFCC). Pemotongan silence ini dilakukan di awal dan di akhir sinyal suara tangis bayi.

Ekstraksi ciri merupakan proses untuk menentukan satu nilai atau vektor yang dapat digunakan sebagai penciri objek atau individu. Ciri yang biasa digunakan adalah koefisien cepstral dari sebuah frame. MFCC merupakan ekstraksi ciri yang menghitung koefisien cepstral dengan mempertimbangkan pendengaran manusia (Buono 2009). Diagram alur dari MFCC dapat dilihat pada Gambar 2.

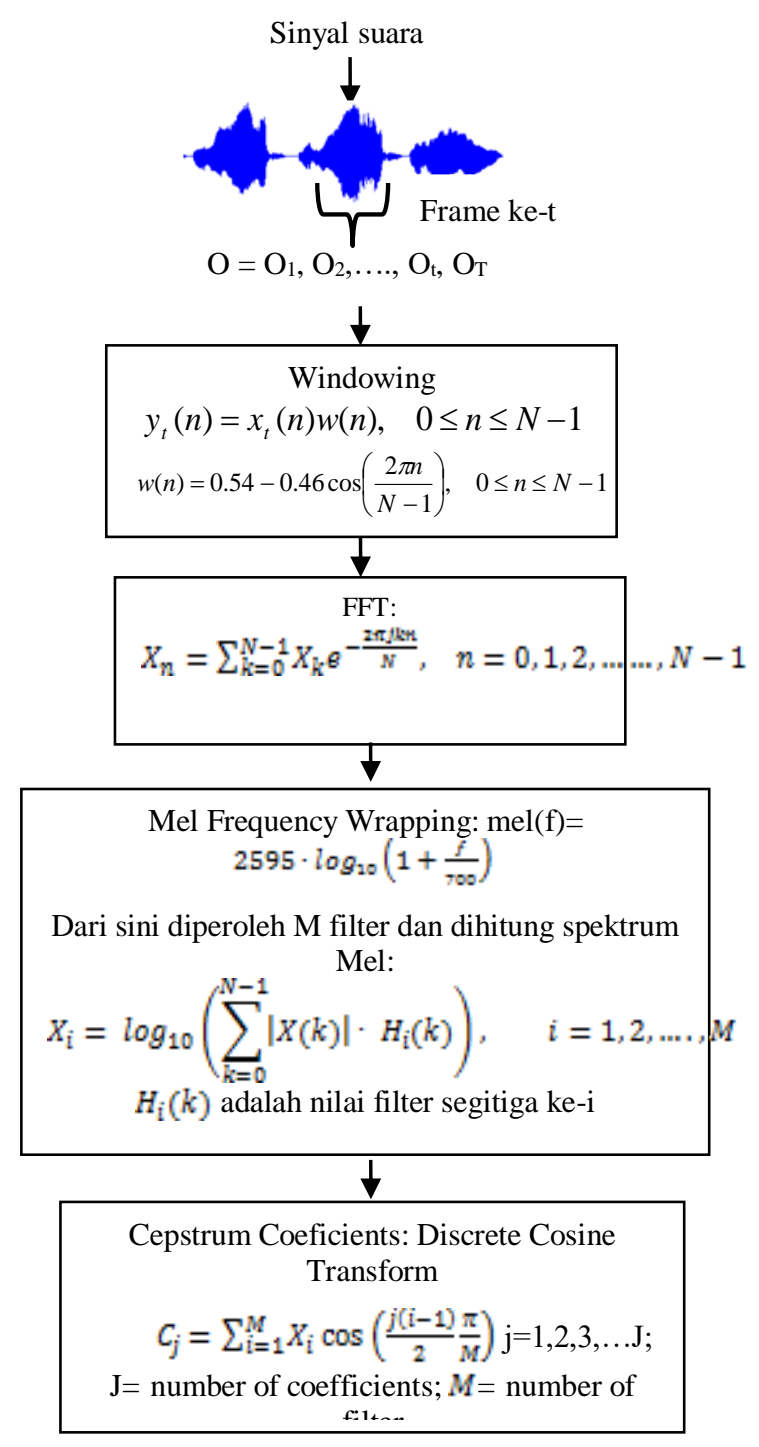

Gambar 2 Diagram Alur MFCC

\section{Pemodelan Codebook Tangis Bayi}

Pemodelan codebook ini berasal dari setiap data latih yang nantinya digunakan sebagai representasi sinyal tangis bayi yang akan dikenali. Codebook yang akan dibuat yaitu codebook dari setiap data tangis bayi. Codebook dari cluster yang dibuat berasal dari hasil clustering semua data tangis bayi dengan menggunakan $k$ means clustering.

Vector Quantization (VQ) merupakan proses memetakan vektor-vektor dari ruang vektor yang besar menjadi ruang vektor dengan jumlah terbatas. Setiap daerah disebut cluster dan dapat direpresentasikan oleh pusatnya yang disebut codeword. Kumpulan codeword disebut codebook (Do 1994). Pemodelan speaker menggunakan pendekatan berbasis $\mathrm{VQ}$ dibentuk oleh clustering dari fitur speaker pada $\mathrm{K}$ yang tidak 
overlapping. Setiap cluster direpresentasikan oleh code vector ci yang disebut centroid. Hasil himpunan code vector ini disebut codebook. Codebook ini berfungsi sebagai model pembicara (Linde et al. 1980).

K-means clustering merupakan algoritma clustering eksklusif. Setiap objek ditetapkan secara tepat ke dalam salah satu dari sekumpulan cluster. Metode clustering ini dimulai dengan menentukan banyaknya cluster yang akan dibentuk (disebut dengan nilai k). Nilai k umumnya nilai integer terkecil seperti 2, 3, 4, atau 5 . Pengukuran kualitas satu cluster dapat menggunakan nilai dari fungsi objektif yang diambil dari jumlah kuadrat jarak setiap titik dari centroid yang telah ditentukan (euclidean distance). Pilih poin k yang umumnya sesuai dengan lokasi k dari suatu objek. Poin k ini nantinya dijadikan sebagai centroid dari k cluster. Metode ini dapat bekerja maksimal jika pemilihan poin awal k yang berjauhan. Selanjutnya dipilih setiap poin, satu per satu dari suatu cluster yang mempunyai centroid terdekat. Semua objek mempunyai k cluster berdasarkan $\mathrm{k}$ initial centroid tetapi 'centroid' ini tidak akan menjadi centroid sejati suatu cluster. Langkah selanjutnya dihitung ulang centroid dari cluster dan dilakukan langkah-langkah sebelumnya untuk menempatkan setiap objek ke cluster dengan centroid terdekat. Algoritma k-means clustering sebagai berikut (Bramer 2007):

1. Pilih nilai $\mathrm{k}$

2. Pilih objek k secara acak. Objek ini akan menjadi $k$ initial centroid

3. Tetapkan setiap objek dari suatu cluster yang terdekat dengan centroid

4. Hitung ulang centroid dari k cluster

5. Ulangi langkah 3 dan 4 sampai perubahan nilai centroid pada iterasi satu dengan lainnya tetap (centroid tidak bergerak

Tahap pembuatan codebook untuk seorang pembicara sebagai berikut (Buono 2009):

1. Untuk setiap pengucapan (ada $n$ pengucapan sebagai data training), dilakukan ekstraksi ciri menggunakan MFCC pada setiap frame dengan panjang dan overlap tertentu.

2. Semua frame dari $n$ pengucapan digabungkan menjadi satu set dan dilakukan unsupervised clustering menggunakan teknik k-means clustering dengan memilih banyaknya cluster sesuai dengan jumlah codeword yang diinginkan.

\section{Pengujian dan Analisis}

Tahapan pengujian berarti melakukan pengujian untuk identifikasi jenis tangis bayi. Alur proses untuk tahap identifikasi/pengenalan adalah (Buono 2009):

1. Untuk setiap ucapan baru yang masuk ke sistem dibaca frame demi frame, (misalkan jumlah frame yang diperoleh adalah T), dan dilakukan ekstraksi ciri menggunakan MFCC

2. Hitung jarak sinyal input ucapan ini ke codebook setiap pembicara yang ada dalam sistem.

3. Keputusan: menetapkan label pada input suara sesuai dengan pembicara dengan jarak codebook terkecil.

Jarak input ucapan dengan codebook dirumuskan sebagai berikut (Buono 2009):

1. Untuk setiap frame dari input ucapan yang masuk, hitung jarak ke setiap codeword dan dipilih codeword dengan jarak minimum.

2. Jarak antara input ucapan dengan codebook adalah jumlah dari jarak minimum tersebut (persamaan 1):

$$
\begin{aligned}
& \text { jarak (input, codebook) }= \\
& \sum_{t=1 \text { wcodeword }}^{T}\left[d\left(\text { frame }_{\mathrm{t}}, \text { codeword }_{k}\right)\right]
\end{aligned}
$$

Penelitian ini menggunakan jarak mahalanobis untuk identifikasi arti tangis bayi. Jarak mahalanobis didefinisikan pada persamaan 2 (Gomathy et al. 2012).

$$
D=\sqrt{\left(x_{g}-y_{g}\right) * C^{-1} *\left(x_{g}-y_{g}\right)^{T}}
$$

C adalah covariance matrix, $\mathrm{x}=\left\{\mathrm{x}_{1}, \mathrm{x}_{2}, \ldots . \mathrm{x}_{\mathrm{s}}\right\}^{\top}$ dan $\mathrm{y}=\left\{\mathrm{y}_{1}, \mathrm{y}_{2}, \ldots, \mathrm{y}_{\mathrm{s}}\right\}^{\top}$

Pengujian dilakukan menggunakan data uji sebanyak 35 dan data latih yang berjumlah 140. Tahap analisis dilakukan berdasarkan hasil yang didapatkan pada tahap pengujian. Analisis dilakukan berdasarkan hasil dari kombinasi faktor dan level berikut:

- $\quad$ panjang frame : $25 \mathrm{~ms} /$ panjang frame 275, $40 \mathrm{~ms} /$ panjang frame 440, $60 \mathrm{~ms} /$ panjang frame 660 .

- overlap frame : $0 \%, 25 \%, 40 \%$.

- $\quad$ banyaknya codeword/jumlah cluster: 1 sampai dengan 18 . Untuk panjang frame = 275 dan overlap frame $=0$, jumlah $\mathrm{k}$ adalah 1-29 cluster.

Masing-masing kombinasi faktor dan level tersebut akan dihitung nilai akurasi menggunakan persamaan 3.

akurasi $=$

jumiah data pengujian dengan identifikasi benay $\approx 100 \%$ jumiah data pengujian 


\section{Pembuatan Antarmuka}

Pembuatan antarmuka identifikasi jenis tangis bayi dibuat berdasarkan data latih yang menghasilkan akurasi tertinggi.

\section{HASIL DAN PEMBAHASAN}

Penelitian ini dibuat menggunakan software Matlab R2010b version 7.11.0.584. Hasil perbandingan akurasi pengujian data uji ditampilkan pada Gambar 3.

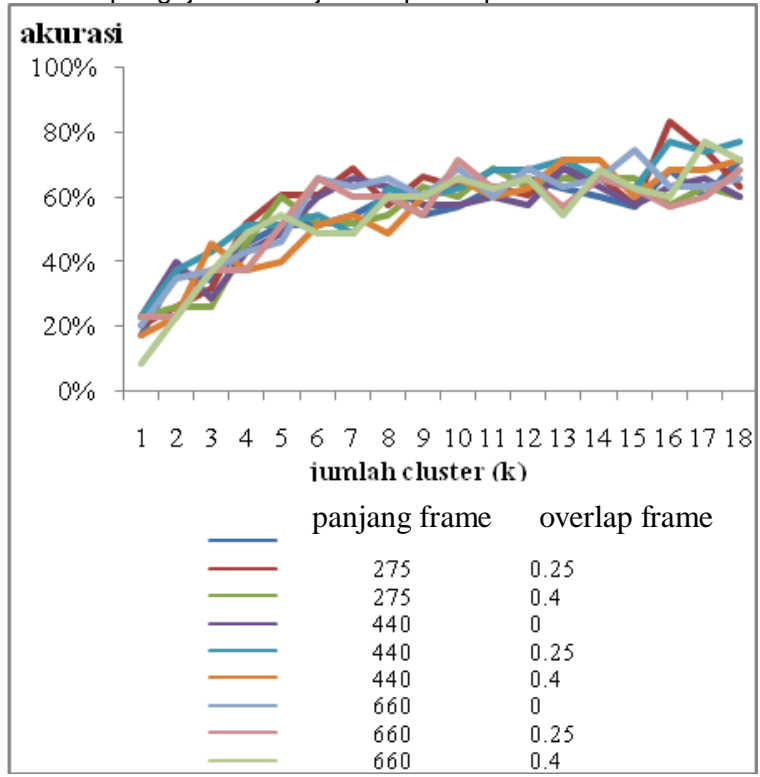

Gambar 3 Grafik perbandingan pengujian data uji

Grafik perbandingan akurasi menggunakan pengujian data latih ditampilkan pada Gambar 4 .

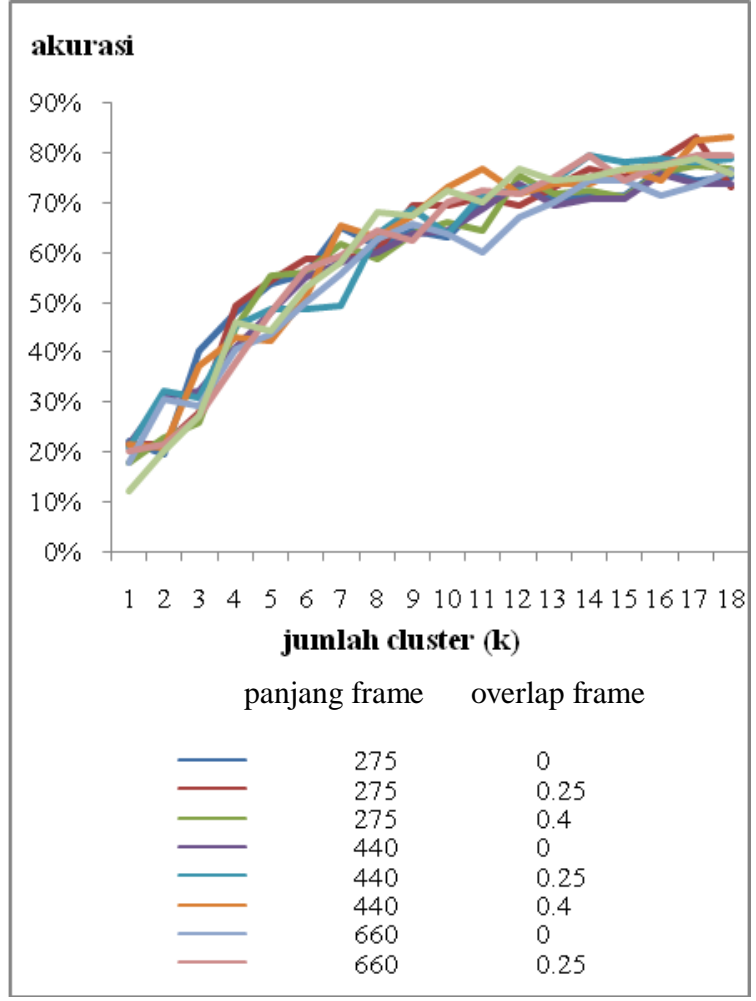

Gambar 4 Grafik perbandingan pengujian data latih 
Akurasi menggunakan pengujian data uji berkisar antara 9\% sampai $83 \%$. Nilai akurasi $83 \%$ didapat ketika panjang frame $=275$, overlap frame 0.25 , dan $k=16$. Sedangkan akurasi pengujian menggunakan data latih berkisar antara $12 \%$ sampai $83 \%$. Nilai akurasi $83 \%$ diperoleh ketika panjang frame $=275$, overlap frame 0.25 , dan $\mathrm{k}=17$ serta panjang frame $=440$, overlap frame 0.4 , dan $\mathrm{k}=18$. Dari beberapa model yang menghasilkan akurasi tertinggi tersebut, model yang akan digunakan untuk identifikasi adalah model dengan panjang frame $=275$, overlap frame $=0.25, k=17$ karena pengujian yang digunakan menggunakan data latih yang jumlah data latihnya jauh lebih besar dibandingkan data uji. Hasil pengujian ketika $k=17$, panjang frame $=$ 275 , dan overlap frame $=0.25$ ditampilkan pada Tabel 1 . 
Tabel 1 Hasil pengujian data latih saat $k=17$, panjang frame $=275$, dan overlap frame $=0.25$

\begin{tabular}{|c|c|c|c|c|c|c|c|c|c|c|c|c|c|c|c|c|c|c|c|c|c|c|c|c|c|c|c|c|}
\hline \multicolumn{7}{|c|}{ Uji Data Ke- } & & & & & & & & & & & & & & & & & & & & & & \multirow{2}{*}{ Jenis Tangis } \\
\hline 1 & 2 & 3 & 4 & 5 & 6 & 7 & 8 & 9 & 10 & 11 & 12 & 13 & 14 & 15 & 16 & 17 & 18 & 19 & 20 & 21 & 22 & 23 & 24 & 25 & 26 & 27 & 28 & \\
\hline 'a' & 'a' & 'a' & 'a' & 'a' & 'a' & 'a' & 'a' & 'a' & 'a' & 'a' & 'a' & 'a' & 'a' & 'n' & 'a' & 'a' & 'n' & 'e' & 'a' & 'a' & 'a' & 'a' & 'a' & 'a' & 'a' & 'a' & 'a' & a-eairh \\
\hline 'e' & 'e' & 'e' & 'n' & 'e' & 'e' & 'e' & 'e' & 'e' & 'e' & 'h' & 'e' & 'o' & 'e' & 'e' & 'n' & 'e' & 'e' & 'e' & 'e' & 'e' & 'e' & 'e' & 'h' & 'e' & 'e' & 'e' & 'e' & e-eh \\
\hline 'h' & 'h' & 'h' & 'h' & 'h' & 'h' & 'h' & 'h' & 'h' & 'e' & 'h' & 'h' & 'h' & 'h' & 'h' & 'h' & 'h' & 'h' & 'h' & 'h' & 'h' & 'h' & 'h' & 'e' & 'h' & 'h' & 'h' & 'h' & h-heh \\
\hline 'n' & 'n' & 'n' & 'n' & 'n' & 'n' & 'n' & 'n' & 'n' & 'n' & 'n' & 'n' & 'n' & 'h' & 'e' & 'n' & 'n' & 'n' & 'n' & 'h' & 'n' & 'n' & 'a' & 'n' & 'n' & 'n' & 'n' & 'n' & n-neh \\
\hline 'a' & 'o' & 'o' & 'o' & 'o' & 'o' & 'o' & 'n' & 'o' & 'n' & 'o' & 'a' & 'n' & 'o' & 'a' & 'o' & 'e' & 'o' & 'o' & 'a' & 'o' & 'o' & 'o' & 'o' & 'a' & 'h' & 'o' & 'o' & o-owh \\
\hline
\end{tabular}

keterangan:

salah identifikasi 
Dari beberapa hasil pengujian tersebut dapat diketahui bahwa suara 'heh' merupakan suara yang sering benar dikenali. Sedangkan suara 'owh' merupakan suara yang sering salah dikenali dan biasanya kesalahannya dikenali sebagai suara 'neh' dan 'eairh'. Kesalahan identifikasi ini disebabkan karena variasi data latih 'owh' lebih besar dibandingkan dengan yang lain. Ilustrasi codebook 'heh' dan 'owh' pada saat k=17, panjang frame $=275$, dan overlap frame $=0.25$ ditampilkan pada Gambar 5 .

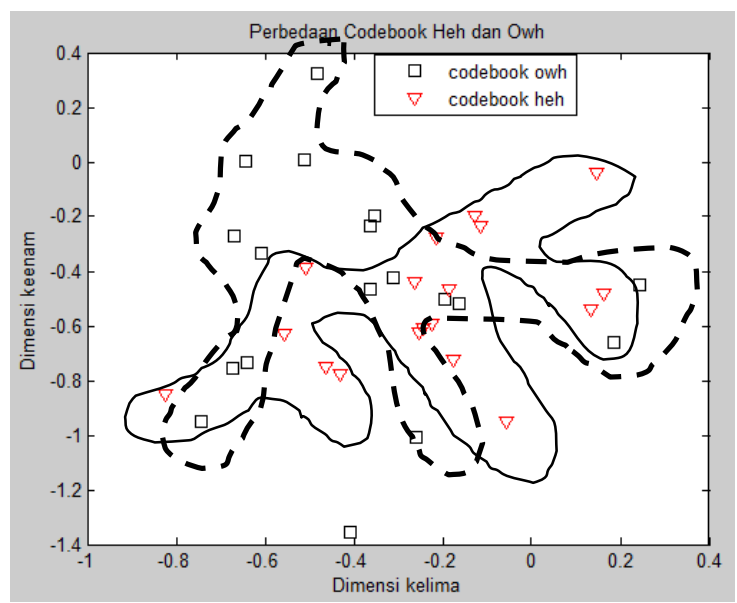

Gambar 5 llustrasi codebook 'heh' dan 'owh'

Perbedaan hasil akurasi menggunakan pengujian data latih dan datauji ditampilkan pada Gambar 6. Akurasi tersebut untuk panjang frame $=275$, overlap frame $=0.25$, jumlah cluster $(k)=1 \mathrm{~s} / \mathrm{d} 29$. Jumlah cluster di sini dibuat lebih banyak dengan tujuan supaya dapat menggambarkan perbedaannya.

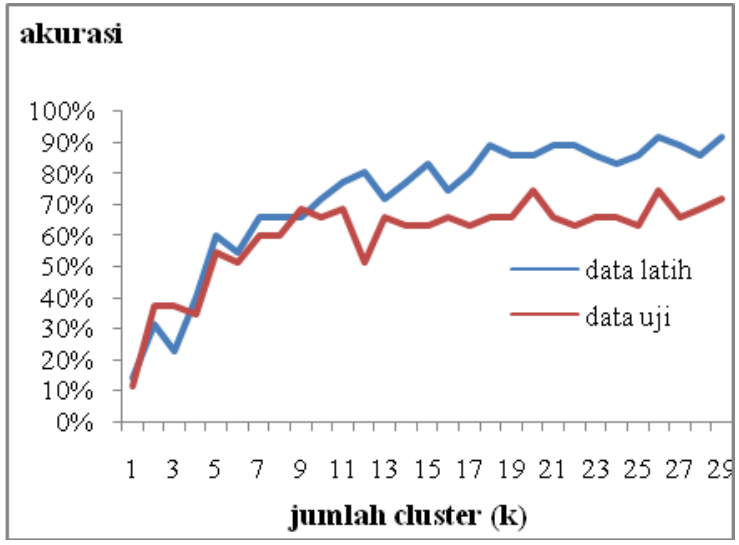

Gambar 6 Akurasi pengujian data latih dan data uji dengan panjang frame $=275$ dan overlap frame $=0$

Gambar 6 menunjukkan akurasi menggunakan data latih lebih tinggi dibandingkan data uji. Hal ini dikarenakan pada jarak mahalanobis sudah ada pembagi variasi sehingga akurasi data latih lebih bagus.

Confusion matrix saat $\mathrm{k}=17$, panjang frame $=275$, dan overlap frame $=0.25$ menggunakan jarak mahalanobis ditampilkan pada Tabel 2.

Tabel 2 Confusion matrix saat $\mathrm{k}=17$, panjang frame $=275$, dan overlap frame $=0.25$

\begin{tabular}{lcccccc}
\hline $\begin{array}{l}\text { Jenis Tangis } \\
\text { Bayi }\end{array}$ & Eairh & Eh & Heh & Neh & Owh & Akurasi \\
\hline Eairh & 25 & 1 & 0 & 2 & 0 & $89 \%$ \\
Eh & 0 & 23 & 2 & 2 & 1 & $82 \%$ \\
Heh & 0 & 2 & 26 & 0 & 0 & $93 \%$ \\
Neh & 1 & 1 & 2 & 24 & 0 & $86 \%$ \\
Owh & 5 & 1 & 1 & 3 & 18 & $64 \%$ \\
\hline & & & & Rata-rata & $82.80 \%$ \\
\hline
\end{tabular}


Antarmuka identifikasi arti tangis bayi ditampilkan pada Gambar 7. Model codebook adalah model dengan panjang frame $=275$, overlap frame $=0.25, \mathrm{k}=17$.

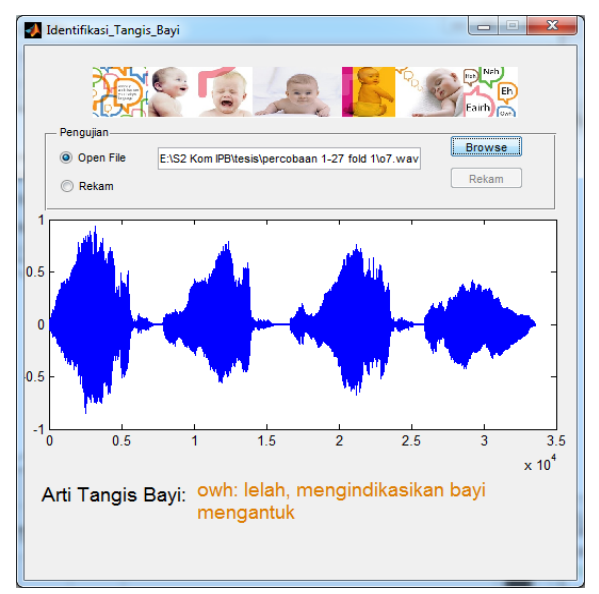

Gambar 7 Antarmuka identifikasi arti tangis bayi

\section{SIMPULAN}

Software ini digunakan untuk identifikasi jenis tangis bayi versi Dunstan Baby Language. Identifikasi ini menggunakan codebook untuk pengenal pola dan MFCC untuk ekstraksi ciri. Penelitian ini memvariasikan panjang frame, overlap frame, dan banyaknya codeword. Model codebook dan MFCC yang menghasilkan akurasi tertinggi yaitu: panjang frame $=275$, overlap frame $=0.25, k=17$ dengan akurasi $83 \%$.

\section{DAFTAR PUSTAKA}

Bramer M. 2007. Principles of Data Mining. London: Springer.

Buono A. 2009. Representasi Nilai HOS dan Model MFCC sebagai Ekstraksi Ciri pada Sistem Indentifikasi Pembicara di Lingkungan Ber-noise Menggunakan HMM. [disertasi]. Depok: Program Studi IImu Komputer, Universitas Indonesia.

Do MN. 1994. Digital Signal Processing Mini-Project: An Automatic Speaker Recognition System. Audio Visual Communication Laboratory, Swiss Federal Institute of Technology, Lausanne, Switzerland.

Dunstan P. 2006. Open Up and Discover Your Baby's Language. [Internet]. [diunduh 2012 Maret 19]. Tersedia pada: http://www.babytaal.nl/media/PDF/ Comprehensive Booklet(2).pdf.

Gomathy M, Meena K, Subramaniam KR. 2012. Gender Clustering and Classification Algorithms in Speech Processing: A Comprehensive Performance Analysis. International Journal of Computer Applications 51(20): 9-17.

Gunawan A. 2011. Dunstan Baby Language Indonesia. [Internet]. [diunduh 2012 September 8]. Tersedia pada: http://www.mommeworld.com/ post/view/49/ dunstan-baby-language-indonesia/.

Kumar C. Rao PM. 2011. Design of an Automatic Speaker Recognition System using MFCC, Vector Quantization, and LBG Algorithm. International Journal on Computer Science and Engineering (IJCSE) 3(8): 2942-2954.

Lederman D, Zmora E, Hauschildt S, Stellzig-Eisenhauer A, Wermke K. 2008. Classification of cries of infants with cleft-palate using parallel hidden Markov models. International Federation for Medical and Biological Engineeering 46: 965-975.

Lee C, Lien C, Huang R. 2006. Automatic Recognition of Birdsongs Using Mel-frequency Cepstral Coefficients and Vector Quantization. International MultiConference of Engineers and Computer Scientists; 2006 June 20-22; Hong Kong.

Linde Y, Buzo A, Gray RM. 1980. An Algorithm for Vector Quantizer Design. IEEE Transactions On Communications 28(1): 84-95.

Poel M, Ekkel T. 2006. Analyzing Infant Cries Using a Committee of Neural Networks in order to Detect Hypoxia Related Disorder. International Journal on Artificial Intelligence Tools (IJAIT) 15(3): $397-410$.

Reyes-Galaviz OF, Reyes-Garcia CA. 2004. A System for the Processing of Infant Cry to Recognize Pathologies in Recently Born Babies with Neural Networks. International Speech Communication Association; 2004 September 20-22; Rusia.

Singh S, Rajan EG. 2011. Vector Quantization Approach for Speaker Recognition using MFCC and Inverted MFCC. International Journal of Computer Applications 17(1): 1-7. 